\title{
Attenuation of the Pressor Response to Laryngoscopy and Endotracheal Intubation with Different Intravenous Doses of Esmolol
}

\author{
Amit Manhas ${ }^{1}$, Shallu Jamwal'2, Sachin Gupta ${ }^{3^{*}}$, Nandita Mehta ${ }^{4}$ \\ ${ }^{1} \mathrm{MD}$ (Anaesthesiology), Lecturer, Department of Urology Anaesthesia, \\ Superspeciality Hospital, GMC Jammu, J\&K, India. \\ 2MD(Gynae \& Obstretics), Medical Officer, J\&K Health Services, Jammu, J\&K, India. \\ $3^{*}$ MS (ENT), Assistant Professor, Department of ENT \& HNS, ASCOMS, Sidhra, Jammu, India. \\ ${ }^{4} \mathrm{MD}$ (Anaesthesiology), Professor and Head, Department of Anaesthesiology and Intensive Care, ASCOMS, Sidhra, \\ Jammu, India.
}

\section{ABSTRACT}

Aim: To find out the most effective dose of beta adrenoreceptor blocker esmolol for attenuation of pressor response.

Settings and Design: Prospective, hospital-based.

Subjects and Methods: A total of 100 patients randomly divided into four groups of 25 each were included who were ASA-I i.e.18 years old and above, of both sexes. Group I, II, III and IV received $0,1,2$ and $3 \mathrm{mg} / \mathrm{kg}$ of esmolol hydrochloride diluted in $10 \mathrm{ml}$ of dextrose $5 \%$ slowly injected over a period of 15-20 seconds. Baseline parameters i.e. heart rate (HR), systolic blood pressure (SBP), diastolic blood pressure (DBP) mean arterial pressure (MAP), oxygen saturation $\left(\mathrm{SpO}_{2}\right)$ and electrocardiography (ECG) were recorded. These parameters were again recorded at 30 seconds after administration of propofol, at 1 and 2 minutes after esmolol administration and at $1,3,5$ and 10 minutes after intubation.

Results: Values of baseline parameters and at 30 seconds after giving propofol were comparable. Oxygen saturation $\left(\mathrm{SpO}_{2}\right)$ in all the four groups did not show any variation at all intervals i.e. baseline, 30 seconds after propofol, 1 and 2 minutes after administration of the study drug, 1, 3, 5 and 10 minutes after intubation. A decrease in HR, SBP, DBP and MAP was observed in Groups II, III and IV when compared to their individual baseline values which started at 1 minute after the administration of the study drug. However, there was an increase in mean HR, SBP, DBP and MAP seen immediately

\section{INTRODUCTION}

Laryngoscopy and tracheal intubation are synonymous with modern anaesthesia. As a matter of fact, the rapid strides made by anaesthesia specialty can be directly attributed to our ability to manage the airway. Induction of anaesthesia, intubation of the trachea, and surgical stimulation often invoke cardiovascular response characterized by increases in arterial blood pressure, changes in heart rate and disturbances in cardiac rhythm. These responses are believed to be due to the vagolytic action of drugs which are given to induce anaesthesia and to produce muscle relaxation ${ }^{1}$ but may also arise from reflex sympathoadrenal discharge. ${ }^{2}$ Hypertension and tachycardia have been recognized since 1950 as commonly associated with intubation under light
1 minute after intubation in Groups I and II when compared with their individual baseline values. Whereas, in Group III and IV the mean values for the various parameters were comparable to the baseline. No rhythm disturbance was seen in the ECG in any of the groups.

Conclusion: Intravenous esmolol in a dose of $1 \mathrm{mg} / \mathrm{kg}$ body weight is ineffective in blunting the haemodynamic responses to laryngoscopy and intubation, but esmolol in a dose of 2 $\mathrm{mg} / \mathrm{kg}$ body weight given 3 minutes before laryngoscopy and endotracheal intubation is effective in attenuating the haemodynamic responses, without any deleterious effects.

Key Words: Attenuation, Esmolol, Intubation, Laryngoscopy.

\section{${ }^{*}$ Correspondence to:}

Dr Sachin Gupta,

MS (ENT), Assistant Professor,

Department of ENT \& HNS, ASCOMS, Sidhra, Jammu, India.

Article History:

Received: 15-07-2016, Revised: 29-07-2016, Accepted: 23-08-2016

\begin{tabular}{|l|c|}
\hline \multicolumn{2}{|c|}{ Access this article online } \\
\hline $\begin{array}{l}\text { Website: } \\
\text { www.ijmrp.com }\end{array}$ & Quick Response code \\
\hline $\begin{array}{l}\text { DOI: } \\
\text { 10.21276/ijmrp.2016.2.5.017 }\end{array}$ & \\
\hline
\end{tabular}

anaesthesia. ${ }^{3}$ King et al. ${ }^{4}$, Forbes and Dally ${ }^{5}$, Hassen et al. ${ }^{6}$ proposed that the mechanism of haemodynamic and catecholamine response to endotracheal intubation is that of somatovisceral reflex.

Direct laryngoscopy activates proprioceptors at the base of the tongue which induces arterial hypertension, tachycardia and increased plasma catecholamines in proportion to the magnitude of stimulus. Subsequent intubation stimulates the receptors in the larynx and trachea with enhancement of haemodynamic and epinephrine response. The rise in blood pressure and heart rate on laryngoscopy and/or endotracheal intubation is transitory, variable and unpredictable. ${ }^{7}$ Intubation following barbiturate and 
suxamethonium induction is accompanied by a $25-50$ percent increase in mean arterial pressure and heart rate beginning with laryngoscopy, peaking at 1-2 minutes and reaching the baseline within 5-10 minutes. Forbes and Dally 5 established that the mean increase in arterial pressure due to laryngoscopy and endotracheal intubation is of the order of $20-26 \mathrm{mmHg}$ with a maximum rise of about $40-45 \mathrm{mmHg}$. The peak response occurs about 30-45 seconds after laryngoscopy. ${ }^{8}$ These complications are generally of no serious consequence in normotensive patients but may be exaggerated and hence more hazardous in patients with hypertension, coronary artery disease, cerebrovascular disease, myocardial infarction, thyrotoxicosis and various other conditions. ${ }^{9}$ So far, numerous techniques have been utilized for blunting the haemodynamic response to laryngoscopy and intubation with variable degree of success.

Lignocaine is the most commonly used local anaesthetic drug for attenuation of the stress response to laryngoscopy and intubation due to its analgesia, ${ }^{10}$ antiarrhythmic effect, ${ }^{11}$ rapid onset, short duration of action and suppression of laryngeal reflexes. However, topical and intravenous lignocaine has been found to be inconsistently effective., $7,12,13$ Sodium nitroprusside, an antihypertensive agent, has a relatively balanced effect on both arterial and venous pressure and a direct effect on the myocardium. ${ }^{14}$ However, it produces thiocyanate and cyanide toxicity, ${ }^{15}$ methemoglobinem ${ }^{16}$ and acute phlebitis. ${ }^{14}$ Nitroglycerine, as sublingual tablets, parentrally, topically as intranasal solution or as a topical ointment decreases blood pressure effectively and the effect is rapidly reversible. Neuroleptanalgesics, opiods, clonidine, hydralazine, calcium channel blockers and other wide variety of drugs have been used to attenuate the pressor response to laryngoscopy and endotracheal intubation with varying degrees of success. Not many techniques have achieved widespread acceptance because either the reflex is not completely blocked or the agent used are long acting and have undesirable side effects. $\beta$-adrenergic blockers have been recommended by Pyrs-Roberts et al. ${ }^{9}$ to attenuate the pressor response associated with laryngoscopy and endotracheal intubation as the response is sympathetically mediated. ${ }^{17}$ Lower incidence of dysrythmias were reported in patients receiving metaprolol. Prys-Roberts et al. ${ }^{18}$ used practolol, Bernstein et al. ${ }^{19}$ successfully used intravenous labetalol to attenuate the pressor response.

Esmolol is also an addition to this group of drugs and many studies have been done comparing esmolol with other agents like lignocaine, fentanyl etc. ${ }^{13,20.21}$ Jacque et al. ${ }^{22}$ observed that both doses of esmolol (100 and $150 \mathrm{mg}$ ) given intravenous 2 minutes before intubation provided protection against the rise in heart rate but not hypertension. Esmolol is an ultra-short acting, cardioselective beta-blocker that is rapidly metabolized by both blood and liver esterases such that its elimination half-life in man is $9.2 \pm 2$ minutes. ${ }^{23,24}$ These properties suggest that esmolol is better than other beta-blockers for attenuation of stress response to laryngoscopy and intubation. Esmolol in dose of $1.5 \mathrm{mg} / \mathrm{kg}$ i.v. bolus, administered 3 minutes before intubation, safely and effectively attenuates the cardiovascular stress response to laryngoscopy and endotracheal intubation..$^{25,26}$

Esmolol, which is an ultra-short acting cardio-selective beta-1 adrenoceptor blocker, seems to be an ideal choice for attenuation of pressor response and therefore need more studies to evaluate its usefulness. The present study was therefore undertaken to evaluate the different intravenous doses of short acting betablocker esmolol to attenuate the pressor response to laryngoscopy and endotracheal intubation.

\section{MATERIALS AND METHODS}

The present study was a prospective study conducted in the Department of Anaesthesiology and Intensive Care in Acharya Shri Chander College of Medical Sciences and Hospital (Jammu) for a period of one year commencing from November 2006 to October 2007. The study included 100 patients of both the sexes admitted in the department of Anaesthesiology and Intensive Care who were ASA- I adult patients i.e. 18 years old and above, of both sexes posted for routine surgery under general anaesthesia having no history of hypertension or pre-existing cardiovascular disease, diabetes and asthma were taken-up in the study. Preanaesthetic check-up was done one day prior to surgery and included a detailed history, a thorough physical examination and basic investigations. The patients were randomly divided into four groups of 25 each. Patients predicted to have a difficult airway (i.e. Malampati score 3 and 4) were excluded from the study. An informed consent was taken from all the patients included in the study at the time of preanaesthetic evaluation.

\section{Pre-medication}

Patient was prepared by overnight fasting and premedicated with tab. diazepam $10 \mathrm{mg}$ at bed time and tab. diazepam $5 \mathrm{mg}$ in the morning on the day of surgery.

Group I: Patients received $10 \mathrm{ml}$ of dextrose $5 \%$, which was injected over a period of 15-20 seconds.

Group II: Patients received $1 \mathrm{mg} / \mathrm{kg}$ of esmolol hydrochloride diluted

$10 \mathrm{ml}$ of dextrose $5 \%$ and slowly injected over a period of $15-20$ seconds.

Group III: Patients received $2 \mathrm{mg} / \mathrm{kg}$ of esmolol hydrochloride diluted in $10 \mathrm{ml}$ of dextrose $5 \%$ and slowly injected over a period of $15-20$ seconds.

Group IV: Patients received $3 \mathrm{mg} / \mathrm{kg}$ of esmolol hydrochloride diluted in $10 \mathrm{ml}$ of dextrose $5 \%$ and slowly injected over a period of $15-20$ seconds.

\section{Anaesthetic Technique}

After receiving the patients in the operation threatre all the baseline parameters i.e., heart rate, blood pressure, oxygen saturation and electrocardiograph were noted. The patients were givens injection ondansteron $8 \mathrm{mg}$ followed by tramadol 0.5 $\mathrm{mg} / \mathrm{kg}$. The patients were then preoxygenated with $100 \%$ oxygen for 3 minutes, using a face mask. Anaesthesia was induced with injection propofol $2.5 \mathrm{mg} / \mathrm{kg}$ given over 15 seconds. Thirty seconds after injection of propofol, all the above mentioned parameters were noted again. The studied drug which was prepared by a trained anaesthetic technician and was unknown to the observer was then given to the patient over a period of 15-20 seconds followed immediately by injection rocuronium $0.8 \mathrm{mg} / \mathrm{kg}$. Parameters were noted after 1 minute and then at 2 minutes after administration of study drug. Patients were intubated with proper sized, cuffed endotracheal tube and air entry was checked for the proper placement of the endotracheal tube. Next recording of parameters was done 1 minute after intubation. Anesthesia was maintained with halothane as required by the patient, nitrous oxide $66 \%$ in oxygen. Then further readings of the parameters were 
noted at 3 minutes, 5 minutes and 10 minutes after intubation. Any untoward incident in the form of arrhythmias, bradycardia, hypotension, asthma and bronchospasm were noted. The nature of the studied drug was revealed to the observer after the completion of the case.

\section{Statistical Analysis}

Data analysis was undertaken with the help of computer software SPSS 10.0 for Windows. Baseline characteristics were found to be comparable. Haemodynamic variables were reported as mean and standard deviation. Statistical significance among groups was evaluated using one-way Analysis of Variance. Post-hoc comparisons were made using Bonferronie. A p-value of $<.05$ was considered as statistically significant.

\section{RESULTS}

100 patients above the age group of 18 years belonging to ASA physical status I and Mallampati score I and II of either sex, posted for a routine surgery under general anaesthesia were included in the study. The patients were randomly allocated into four groups (25 each) and were given different doses of esmolol diluted in $10 \mathrm{ml}$ of dextrose $5 \%$, which was injected intravenously over 15 to 20 seconds. The study drugs were given at the time of induction. To ensure blindness, the drugs were given by the technician and the identity of the drug was not disclosed to the anaesthesiologist till the end of the study. Data was analysed upto 10 minutes after intubation. Observations were made from all four groups. Parameters were recorded and evaluated statistically.

Table 1: Distribution of patients of different groups according to age (years).

\begin{tabular}{lcccc}
\hline Group & Range & Mean & Standard Deviation $(\mathbf{\pm})$ & Statistical Inference $^{*}$ \\
\hline I $(\mathbf{n}=\mathbf{2 5})$ & $22-55$ & 40.36 & 9.35 & $\mathrm{~F}=2.09$ \\
II $(\mathbf{n}=\mathbf{2 5})$ & $22-45$ & 36.40 & 4.45 & $\mathrm{p}=0.106$ \\
III $(\mathbf{n = 2 5 )}$ & $21-50$ & 37.52 & 7.46 & \\
IV $(\mathbf{n}=\mathbf{2 5})$ & $25-53$ & 40.08 & 7.41 & \\
\hline
\end{tabular}

${ }^{*}$ Repeated measures analysis of variance

Table 2: Distribution of patients of different groups according to sex.

\begin{tabular}{lcccc}
\hline Group & \multicolumn{3}{c}{ Males } & \multicolumn{2}{c}{ Females } \\
\cline { 2 - 5 } & $($ No.) & $(\%)$ & (No.) & $(\%)$ \\
I $(n=25)$ & 7 & 28 & 18 & 72 \\
II $(n=25)$ & 7 & 28 & 18 & 72 \\
III $(n=25)$ & 13 & 52 & 12 & 48 \\
IV $(n=25)$ & 9 & 36 & 16 & 64 \\
\hline
\end{tabular}

$\Pi^{2}(3)=4.17 ; p=0.24 ;$ Non-significant

Table 3: Mean heart rate $\left(\mathrm{min}^{-1}\right)$ in different groups

\begin{tabular}{lcccc}
\hline Time & $\begin{array}{c}\text { Group I } \\
\text { Mean } \pm \text { SD }\end{array}$ & $\begin{array}{c}\text { Group II } \\
\text { Mean } \pm \text { SD }\end{array}$ & $\begin{array}{c}\text { Group III } \\
\text { Mean } \pm \text { SD }\end{array}$ & $\begin{array}{c}\text { Group IV } \\
\text { Mean } \pm \text { SD }\end{array}$ \\
\hline Baseline & $87.52 \pm 11.98$ & $85.12 \pm 11.03$ & $81.72 \pm 8.76$ & $82.20 \pm 17.86$ \\
30 sec after propofol & $84.12 \pm 16.42$ & $86.80 \pm 11.5$ & $84.00 \pm 9.47$ & $85.36 \pm 9.51$ \\
1 min after the drug & $84.72 \pm 10.62$ & $81.76 \pm 10.33$ & $76.56 \pm 9.73$ & $78.02 \pm 6.71$ \\
2 mins after the drug & $83.68 \pm 10.72$ & $77.72 \pm 10.18$ & $73.04 \pm 8.94$ & $72.20 \pm 7.10$ \\
1 min after intubation & $101.56 \pm 9.75$ & $92.6 \pm 7.75$ & $87.48 \pm 9.26$ & $82.00 \pm 8.17$ \\
3 mins after intubation & $96.88 \pm 10.03$ & $89.92 \pm 8.98$ & $83.08 \pm 11.7$ & $78.32 \pm 8.47$ \\
5 mins after intubation & $88.28 \pm 9.08$ & $86.72 \pm 8.22$ & $79.68 \pm 11.83$ & $74.64 \pm 9.25$ \\
10 mins after intubation & $83.49 \pm 9.67$ & $88.16 \pm 6.8$ & $78.08 \pm 10.28$ & $76.48 \pm 8.32$ \\
\hline
\end{tabular}

Table 4: Inter-group comparison of mean heart rate

\begin{tabular}{|c|c|c|c|c|c|c|}
\hline \multirow[t]{2}{*}{ Statistical inference } & \multicolumn{6}{|c|}{ Inter-Group Comparison } \\
\hline & | v/s || & | v/s III & I v/s IV & II v/s III & II v/s IV & III v/s IV \\
\hline $\begin{array}{l}\text { Baseline } \\
F=1.109 ; p=0.35\end{array}$ & - & - & - & - & - & - \\
\hline $\begin{array}{l}30 \mathrm{sec} \text { after propofol } \\
F=0.266 ; p=0.850\end{array}$ & - & - & - & - & - & - \\
\hline $\begin{array}{l}1 \mathrm{~min} \text { after the drug } \\
F=3.59 ; p=0.016\end{array}$ & 1.000 & $0.018^{\star *}$ & $0.014^{* *}$ & 0.332 & 1.000 & 1.000 \\
\hline $\begin{array}{l}2 \text { mins after the drug } \\
F=8.005 ; p=0.0001\end{array}$ & 0.190 & $0.001^{* *}$ & $0.001^{* *}$ & 0.407 & 0.197 & 1.000 \\
\hline $\begin{array}{l}1 \text { min after intubation } \\
F=22.31 ; p=0.0001\end{array}$ & $0.003^{* *}$ & $0.001^{* \star}$ & $0.0001^{* *}$ & 0.250 & $0.0001^{* *}$ & 0.192 \\
\hline $\begin{array}{l}3 \text { mins after intubation } \\
F=16.81 ; p=0.0001\end{array}$ & 0.087 & $0.0001^{* *}$ & $0.0001^{* *}$ & 0.097 & $0.0001^{* *}$ & 0.550 \\
\hline $\begin{array}{l}5 \text { mins after intubation } \\
F=10.70 ; p=0.0001\end{array}$ & 1.000 & $0.014^{* *}$ & $0.0001^{* *}$ & 0.071 & $0.0001^{* *}$ & 0.415 \\
\hline $\begin{array}{l}10 \text { mins after intubation } \\
F=9.05 ; p=0.0001\end{array}$ & 0.388 & 0.201 & $0.038^{*}$ & $0.001^{* *}$ & $0.0001^{* *}$ & 1.000 \\
\hline
\end{tabular}


The age of the patients ranged from 21 to 55 years. Group I and Group IV patients were of slightly higher age groups as compared to Group II and Group III but the difference in age was statistically insignificant. (Table 1)

In Groups I, II and IV, male patients comprised of almost one-third population in sample size study, whereas in Group III, number of male and female patients were almost similar. (Table 2)

Table 3 shows mean heart rate $\left(\mathrm{min}^{-1}\right)$ and their range at different time intervals both before and after administration of the study drug and tracheal intubation in Group I, II, III and IV. The maximum increase in mean heart rate was observed at 1 minute after intubation in groups I, II and III. However, Group III and IV patients showed a decrease in mean heart rate was observed at 1 minute after administering the study drug which persisted till 10 minutes after intubation. Here the value at 3 minutes after intubation was almost comparable to baseline. Highly significant differences were seen between Group I and Group III, and Group I and Group IV. (Table 4)

Table 5 shows mean systolic blood pressure $(\mathrm{mmHg})$ and their range both before and after the administration of the study drug at different time intervals in different groups. The maximum increase in mean systolic blood pressure was observed at 1 minute after intubation in groups I, II and III. However, the values were lower than baseline in groups III and IV and the effect of the drug persisted till 10 minutes after intubation. The differences are highly significant when comparison is made between Group I versus Group III, and Group I versus Group IV.

Table 7,8 shows mean diastolic blood pressure $(\mathrm{mmHg})$ and their range both before and after the administration of the study drug at different time intervals in Group I, II, III and IV. Maximum increase was observed at 1 minute after intubation. However, the values were almost comparable to baseline values in group III. The effect of the drug persisted till 10 minutes after intubation whereas in group IV significant decrease in diastolic blood pressure was observed at 2 minutes after administration of the drug and at 5 minutes after intubation. Values at 10 minute after intubation were comparable to the baseline. The differences are highly significant when comparison is made between Group I versus Group IV.

Table 5: Mean systolic blood pressure ( $\mathrm{mmHg}$ ) in Groups I, II, III and IV

\begin{tabular}{|c|c|c|c|c|c|c|}
\hline \multirow[t]{3}{*}{ Time } & \multicolumn{6}{|c|}{ Mean \pm SD values } \\
\hline & \multicolumn{6}{|c|}{ Groups } \\
\hline & \multicolumn{2}{|c|}{$\frac{I}{1330+1112}$} & II & \multicolumn{2}{|c|}{ III } & \multirow{2}{*}{$\begin{array}{c}\text { IV } \\
132.56 \pm 10.20\end{array}$} \\
\hline Baseline & \multirow{2}{*}{\multicolumn{2}{|c|}{$\begin{array}{l}133.0 \pm 11.12 \\
128.6 \pm 15.07\end{array}$}} & $131.6 \pm 9.36$ & \multicolumn{2}{|c|}{$132.08 \pm 9.63$} & \\
\hline $30 \mathrm{sec}$ after propofol & & & $125.08 \pm 9.19$ & \multicolumn{2}{|c|}{$121.96 \pm 13.01$} & $122.96 \pm 8.90$ \\
\hline $1 \mathrm{~min}$ after the drug & \multicolumn{2}{|c|}{$121.96 \pm 11.22$} & $118.92 \pm 8.22$ & \multicolumn{2}{|c|}{$112.44 \pm 10.68$} & $114.04 \pm 9.51$ \\
\hline 2 mins after the drug & \multicolumn{2}{|c|}{$122.72 \pm 15.15$} & $115.56 \pm 9.51$ & \multicolumn{2}{|c|}{$111.0 \pm 11.33$} & $107.8 \pm 12.72$ \\
\hline 1 min after intubation & \multicolumn{2}{|c|}{$143.36 \pm 27.88$} & $142.0 \pm 10.12$ & \multicolumn{2}{|c|}{$129.08 \pm 11.65$} & $122.32 \pm 14.19$ \\
\hline 3 mins after intubation & \multicolumn{2}{|c|}{$134.04 \pm 11.99$} & $133.76 \pm 10.07$ & \multicolumn{2}{|c|}{$116.84 \pm 10.21$} & $109.60 \pm 8.64$ \\
\hline 5 mins after intubation & \multicolumn{2}{|c|}{$127.84 \pm 14.67$} & $127.88 \pm 8.99$ & \multicolumn{2}{|c|}{$116.40 \pm 11.93$} & $106.68 \pm 9.10$ \\
\hline 10 mins after intubation & \multicolumn{2}{|c|}{$129.4 \pm 9.95$} & $133.96 \pm 11.89$ & \multicolumn{2}{|c|}{$126.20 \pm 11.06$} & $126.56 \pm 8.93$ \\
\hline & b: I & omp & mean systoli & od pres & & \\
\hline \multirow{2}{*}{ Statistical inference } & \multicolumn{6}{|c|}{ Inter-Group Comparison } \\
\hline & | v/s || & | v/s III & I v/s IV & II v/s III & II v/s IV & III v/s IV \\
\hline $\begin{array}{l}\text { Baseline } \\
F=0.089 ; p=0.966\end{array}$ & - & - & - & - & - & - \\
\hline $\begin{array}{l}30 \mathrm{sec} \text { after propofol } \\
F=1.535 ; p=0.209\end{array}$ & - & - & - & - & - & - \\
\hline $\begin{array}{l}1 \text { min after the drug } \\
F=4.83 ; p=0.004\end{array}$ & 1.000 & $0.006^{* *}$ & $0.036^{*}$ & 0.143 & 0.522 & 1.000 \\
\hline $\begin{array}{l}2 \text { mins after the drug } \\
F=6.85 ; p=0.0001\end{array}$ & 0.259 & $0.007^{* *}$ & $0.0001^{* *}$ & 1.00 & 0.172 & 1.000 \\
\hline $\begin{array}{l}1 \text { min after intubation } \\
F=8.41 ; p=0.0001\end{array}$ & 1.000 & $0.028^{*}$ & $0.0001^{* *}$ & 0.062 & $0.001^{* *}$ & 1.00 \\
\hline $\begin{array}{l}3 \text { mins after intubation } \\
F=35.47 ; p=0.0001\end{array}$ & 1.000 & $0.0001^{\star \star}$ & $0.0001^{* *}$ & $0.0001^{* *}$ & $0.0001^{* *}$ & 0.095 \\
\hline $\begin{array}{l}5 \text { mins after intubation } \\
F=20.04 ; p=0.0001\end{array}$ & 1.000 & $0.004^{* *}$ & $0.0001^{* *}$ & $0.004^{* *}$ & $0.0001^{* *}$ & $0.020^{*}$ \\
\hline $\begin{array}{l}10 \text { mins after intubation } \\
F=7.16 ; p=0.0001\end{array}$ & 0.772 & 1.000 & $0.022^{*}$ & 0.063 & $0.0001^{* *}$ & 0.366 \\
\hline
\end{tabular}

Table 7: Mean diastolic blood pressure ( $\mathrm{mmHg}$ ) in Groups I, II, III and IV

\begin{tabular}{|c|c|c|c|c|}
\hline \multirow[t]{3}{*}{ Time } & \multicolumn{4}{|c|}{ Mean \pm SD values } \\
\hline & \multicolumn{4}{|c|}{ Groups } \\
\hline & I & II & III & IV \\
\hline Baseline & $81.80 \pm 8.14$ & $81.84 \pm 8.53$ & $81.84 \pm 6.96$ & $82.56 \pm 3.95$ \\
\hline 30 sec after propofol & $79.80 \pm 11.00$ & $78.12 \pm 6.77$ & $74.84 \pm 8.86$ & $79.04 \pm 5.87$ \\
\hline $1 \mathrm{~min}$ after the drug & $77.92 \pm 11.70$ & $73.6 \pm 8.09$ & $74.0 \pm 11.46$ & $75.2 \pm 10.49$ \\
\hline 2 mins after the drug & $78.72 \pm 11.02$ & $74.36 \pm 11.17$ & $72.32 \pm 10.76$ & $67.40 \pm 11.02$ \\
\hline 1 min after intubation & $97.48 \pm 11.23$ & $90.16 \pm 7.73$ & $84.16 \pm 11.71$ & $78.20 \pm 11.00$ \\
\hline 3 mins after intubation & $88.60 \pm 9.17$ & $84.84 \pm 9.35$ & $76.64 \pm 12.26$ & $70.96 \pm 8.51$ \\
\hline 5 mins after intubation & $82.64 \pm 9.27$ & $79.84 \pm 7.4$ & $77.48 \pm 10.06$ & $69.96 \pm 8.34$ \\
\hline 10 mins after intubation & $82.92 \pm 8.74$ & $83.68 \pm 10.29$ & $83.84 \pm 8.07$ & $80.48 \pm 6.76$ \\
\hline
\end{tabular}


Table 8: Inter-group comparison of mean diastolic blood pressure

\begin{tabular}{|c|c|c|c|c|c|c|}
\hline \multirow[t]{2}{*}{ Statistical inference } & \multicolumn{6}{|c|}{ Inter-Group Comparison } \\
\hline & Iv/s II & I v/s III & Iv/s IV & II v/s III & II v/s IV & III v/s IV \\
\hline $\begin{array}{l}\text { Baseline } \\
F=0.066 ; p=0.978\end{array}$ & - & - & - & - & - & - \\
\hline $\begin{array}{l}30 \mathrm{sec} \text { after propofol } \\
F=1.703 ; p=0.172\end{array}$ & - & - & - & - & - & - \\
\hline $\begin{array}{l}1 \mathrm{~min} \text { after the drug } \\
F=0.872 ; p=0.458\end{array}$ & - & - & - & - & - & - \\
\hline $\begin{array}{l}2 \text { mins after the drug } \\
F=4.56 ; p=0.005\end{array}$ & 0.985 & 0.254 & $0.0031^{* *}$ & 1.00 & 0.165 & 0.702 \\
\hline $\begin{array}{l}1 \text { min after intubation } \\
F=15.32 ; p=0.0001\end{array}$ & 0.095 & $0.0001^{* *}$ & $0.0001^{* *}$ & 0.282 & $0.001^{* *}$ & 0.290 \\
\hline $\begin{array}{l}3 \text { mins after intubation } \\
F=16.05 ; p=0.0001\end{array}$ & 1.000 & $0.0001^{* *}$ & $0.0001^{* *}$ & $0.026^{*}$ & $0.0001^{* *}$ & 0.276 \\
\hline $\begin{array}{l}5 \text { mins after intubation } \\
F=0.949 ; p=0.0001\end{array}$ & 1.000 & 0.346 & $0.0001^{* *}$ & 1.000 & $0.0001^{* *}$ & $0.013^{* *}$ \\
\hline $\begin{array}{l}10 \text { mins after intubation } \\
F=0.822 ; p=0.485\end{array}$ & - & - & - & - & - & - \\
\hline
\end{tabular}

$$
\text { F = ANOVA; 'Significant; "Highly Significant }
$$

Table 9: Mean arterial pressure (mmHg) in Groups I, II, III and IV

\begin{tabular}{lcccc}
\hline Time & \multicolumn{4}{c}{ Mean \pm SD values } \\
\cline { 2 - 5 } & \multicolumn{4}{c}{ Groups } \\
Baseline & I & II & III & IV IV \\
30 sec after propofol & $97.72 \pm 8.51$ & $98.52 \pm 8.78$ & $97.92 \pm 8.26$ & $98.52 \pm 6.59$ \\
1 min after the drug & $98.16 \pm 16.29$ & $93.92 \pm 6.86$ & $90.40 \pm 10.20$ & $92.48 \pm 6.52$ \\
2 mins after the drug & $93.28 \pm 11.82$ & $90.60 \pm 7.89$ & $86.40 \pm 10.04$ & $88.60 \pm 8.24$ \\
1 min after intubation & $94.88 \pm 14.43$ & $88.96 \pm 9.75$ & $85.00 \pm 10.23$ & $80.52 \pm 10.66$ \\
3 mins after intubation & $114.40 \pm 9.39$ & $109.00 \pm 8.77$ & $99.24 \pm 10.66$ & $94.00 \pm 10.12$ \\
5 mins after intubation & $104.64 \pm 10.29$ & $100.72 \pm 10.08$ & $89.68 \pm 11.52$ & $85.16 \pm 8.23$ \\
10 mins after intubation & $98.52 \pm 10.62$ & $96.68 \pm 8.80$ & $88.84 \pm 10.62$ & $82.68 \pm 7.72$ \\
\hline
\end{tabular}

Table 10: Inter-group comparison of mean arterial pressure

\begin{tabular}{|c|c|c|c|c|c|c|}
\hline \multirow[t]{2}{*}{ Statistical inference } & \multicolumn{6}{|c|}{ Inter-Group Comparison } \\
\hline & | v/s || & | v/s ||| & I v/s IV & II v/s III & II v/s IV & III v/s IV \\
\hline $\begin{array}{l}\text { Baseline } \\
F=0.065 ; p=0.978\end{array}$ & - & - & - & - & - & - \\
\hline $\begin{array}{l}30 \text { sec after propofol } \\
F=3.53 ; p=0.018\end{array}$ & - & - & - & - & - & - \\
\hline $\begin{array}{l}1 \text { min after the drug } \\
F=2.31 ; p=0.081\end{array}$ & - & - & - & - & - & - \\
\hline $\begin{array}{l}2 \text { mins after the drug } \\
F=7.11 ; p=0.0001\end{array}$ & 0.420 & $0.017^{* *}$ & $0.0001^{* *}$ & 1.00 & 0.063 & 1.000 \\
\hline $\begin{array}{l}1 \text { min after intubation } \\
F=22.34 ; p=0.0001\end{array}$ & 0.321 & $0.0001^{* *}$ & $0.0001^{* *}$ & $0.004^{* *}$ & $0.0001^{* *}$ & 0.365 \\
\hline $\begin{array}{l}3 \text { mins after intubation } \\
F=20.47 ; p=0.0001\end{array}$ & 1.00 & $0.0001^{* *}$ & $0.0001^{* *}$ & $0.001^{* *}$ & $0.0001^{* *}$ & 0.702 \\
\hline $\begin{array}{l}5 \text { mins after intubation } \\
F=14.77 ; p=0.0001\end{array}$ & 1.0001 & $0.003^{* *}$ & $0.0001^{* *}$ & $0.027^{*}$ & $0.0001^{* *}$ & 0.146 \\
\hline $\begin{array}{l}10 \text { mins after intubation } \\
F=1.594 ; p=0.196\end{array}$ & - & - & - & - & - & - \\
\hline
\end{tabular}

Table 11: Oxygen saturation [ $\mathrm{SpO}_{2} \%$ ] in Groups I, II, III and IV

\begin{tabular}{|c|c|c|c|c|}
\hline \multirow[t]{3}{*}{ Time } & \multicolumn{4}{|c|}{ Mean \pm SD values } \\
\hline & \multicolumn{4}{|c|}{ Groups } \\
\hline & I & ॥ & III & IV \\
\hline Baseline & $99.96 \pm 0.2000$ & $99.92 \pm 0.276$ & $99.56 \pm 0.768$ & $99.84 \pm 0.553$ \\
\hline 30 sec after propofol & $99.92 \pm 0.276$ & $99.92 \pm 0.276$ & $99.76 \pm 0.43$ & $99.72 \pm 0.613$ \\
\hline $1 \mathrm{~min}$ after the drug & - & $99.92 \pm 0.276$ & $99.96 \pm 0.200$ & $99.92 \pm 0.276$ \\
\hline 2 mins after the drug & - & $99.92 \pm 0.276$ & $99.88 \pm 0.331$ & $99.96 \pm 0.2000$ \\
\hline 1 min after intubation & $99.36 \pm 17.99$ & $99.96 \pm 0.2000$ & $99.80 \pm 0.408$ & $99.96 \pm 0.2000$ \\
\hline 3 mins after intubation & $99.96 \pm 0.2000$ & $99.92 \pm 0.276$ & $99.68 \pm 0.476$ & $99.96 \pm 0.2000$ \\
\hline 5 mins after intubation & $99.96 \pm 0.200$ & $99.92 \pm 0.276$ & $99.72 \pm 0.458$ & $99.96 \pm 0.2000$ \\
\hline 10 mins after intubation & $99.96 \pm 0.2000$ & - & $99.68 \pm 0.476$ & $99.96 \pm 0.2000$ \\
\hline
\end{tabular}


Table 9 shows mean arterial pressure $(\mathrm{mmHg})$ and their range both before and after the administration of the study drug at different time intervals in Group I, II, III and IV. The first two groups showed maximum increase was recorded at 1 minute after intubation. In group III the maximum increase was recorded at 1 minute after intubation and at 3 minutes after intubation. The values were lower when compared to baseline. The effect of the drug persisted till 10 minutes after intubation. In group IV all the values recorded since the time of drug administration till 10 minutes after intubation were comparatively lower than the baseline values.

The differences are highly significant when comparison is made between Group I versus Group III and Group I versus Group IV. (Table 10)

Table 11, it is seen that $\mathrm{SpO}_{2}$ is maintained in very close range in all the groups showing no variation in all the four groups at all-time intervals and consequently the comparison was found to be nonsignificant.

\section{DISCUSSION}

The effects of laryngoscopy and tracheal intubation on the cardiovascular system were noted as early as 1940 when Reid and Brace concluded that cardiac reflex could originate in the trachea, larynx, bronchi or lungs. ${ }^{27}$ These reflexes were termed vagovagal since both the afferent and efferent paths of the reflex were assumed to be the vagus nerve. Burnstein et al. ${ }^{28}$ reported that haemodynamic changes could be attributed to the stimulation of cardio-accelerator nerves, implying an increase in cardiac sympathetic tone rather than increase in vagal tone. King et al. ${ }^{4}$ demonstrated that direct laryngoscopy or tracheal intubation was characterised by a rise in blood pressure and heart rate. PrysRoberts et al. ${ }^{9}$ concluded that hypertensive patients were prone to much greater changes in arterial pressure than normotensive patients which could lead to myocardial ischaemia.

Devault et al. ${ }^{29}$ and Derbyshire et al. ${ }^{30}$ demonstrated that not only a noradrenergic response but also a significant adrenergic response occurs suggesting that tracheal intubation was accompanied by increased sympathetic as well as increased sympatho-adrenal activity. Further studies have shown that tracheal intubation is associated with increases in bispectral index (BIS) as well as heart rate and blood pressure. However, normotensive and hypertensive patients showed similar increases in BIS after tracheal intubation indicating that there was no difference in the intubation induced arousal response. The intensity of cardiovascular response to intubation may vary with depth of anaesthesia, the duration and the difficulties encountered during laryngoscopy and intubation as well as patient-dependent variables including age and the history of diabetes, hypertension or cardiovascular disease.

The potential for life threatening complications associated with laryngoscopy and tracheal intubation in patients with coronary artery disease, ${ }^{31}$ systemic hypertension, aneurysmal vascular disease and decreased intra-cranial compliance ${ }^{32}$ is well known. The circulatory pertubations consists of elevation in heart rate $(\mathrm{HR})$ and systemic and pulmonary artery pressure $^{8,9,33}$ which occasionally lead to myocardial ischaemia, heart failure and cerebrovascular catastrophies. ${ }^{13,34,35}$ Hypertension may also increase the cerebral blood flow and intracranial pressure in head injury patients with impaired autoregulation. These changes stem from reflex sympathetic discharge resulting from epipharyngeal and laryngopharyngeal stimulation, associated with increased plasma norepinephrine concentrations ${ }^{20,21,36,37}$ and are marked by increased blood pressure and heart rate.

The quest for effective blockade of these responses has included intravenous or topical lidocaine, vasodilators, adrenergic blockers, narcotics, and inhaled anaesthetics each having its own set of limitations. Beta adrenergic blocking drugs minimize increase in heart rate and myocardial contractility (primary determinants of oxygen consumption) by attenuating the positive chronotropic and ionotropic effects of increased adrenergic activity Out of various beta-adrenergic blocking agents, esmolol, because of its beta (cardioselective) adrenergic receptor blocking properties, and its short duration of action, might be valuable in obtunding cardiovascular responses to laryngoscopy and intubation. Several studies have assessed the effectiveness of esmolol in blunting the haemodynamic alterations induced by larngoscopy. 26,36,37,39-42

In the present study, 100 ASA-I patients above the age group of 18 years of either sex undergoing elective non-cardiac surgery were randomly divided into four groups of 25 each. All the patients were induced with propofol $2.5 \mathrm{mg} / \mathrm{kg}$ body weight. Patients in Group I acted as control and received $10 \mathrm{ml}$ of $5 \%$ dextrose intravenously. Patients in Group II, III and IV were given 1, 2 and 3 $\mathrm{mg} / \mathrm{kg}$ body weight of esmolol hydrochloride diluted in $10 \mathrm{ml}$ of $5 \%$ dextrose intravenously. This was immediately followed by rocuronium $0.8 \mathrm{mg} / \mathrm{kg}$ body weight to facilitate tracheal intubation. Haemodynamic parameters in the form of heart rate, blood pressure (SBP, DBP and MAP), $\mathrm{SpO}_{2}$ were noted at various intervals i.e. at baseline, 30 seconds after proprofol, 1 and 2 minutes after the administration of study drug and 1, 3, 5 and 10 minutes after intubation. During the study period it was ensured that no surgical stimulus was given.

The mean \pm SD values of Age in Groups I, II, III and IV were $40.36 \pm 9.35,36.40 \pm 4.45,37.52 \pm 7.46$ and $40.08 \pm 7.41$, respectively as shown in Table-1. In Groups, I, II, III and IV, the male patients were $28 \%, 28 \%, 52 \%$ and $36 \%$, respectively, whereas the female patients were $72 \%, 72 \%, 48 \%$ and $64 \%$, respectively as shown in Table 2 . The difference in age and sex were statistically non-significant.

The mean \pm SD of heart rate, systolic blood pressure, diastolic blood pressure, mean arterial pressure and oxygen saturation $\left(\mathrm{SpO}_{2}\right)$ in Groups I, II, III and IV are shown in Tables 3, 5, 7, 9 and 11 , respectively. Values of heart rate, systolic blood pressure, diastolic blood pressure, mean arterial pressure and $\mathrm{SpO}_{2}$ in all the four groups were comparable to baseline and at 30 seconds after giving propofol as shown in Tables 3, 5, 7, 9 and 11, respectively. Oxygen saturation $\left(\mathrm{SpO}_{2}\right)$ in all the four groups did not show any variation at all intervals i.e. baseline, 30 seconds after propofol, 1 and 2 minutes after administration of the study drug, 1, 3, 5 and 10 minutes after intubation (Table 11).

\section{Effect on heart rate (HR)}

There was no significant change in heart rate at 1 and 2 minutes after giving the study drug in Group I (placebo). A decrease in heart rate was observed in Groups II, III and IV when compared to their individual baseline values which started at 1 minute after the administration of the study drug. This effect continued till 2 minutes after administration of the study drug (Table 3).

After intubation, the mean $\mathrm{HR}$ values were recorded at 1, 35 and 10 minutes in all the four groups. There was an increase in mean 
HR seen immediately 1 minute after intubation in Groups I, II and III when compared with their individual baseline values i.e. from $87.52 \pm 11.98$ to $101.56 \pm 9.75,85.12 \pm 11.03$ to $92.6 \pm 7.75$, $81.72 \pm 6.76$ to $87.48 \pm 9.26$, respectively. Whereas in Group IV, the mean $\mathrm{HR}$ values were comparable to the baseline i.e. from $82.20 \pm 17.00$ to $82.00 \pm 8.17$ (Table 3). Heart rate is a major determinant of myocardial oxygen consumption and there is increasing evidence that tachycardia is poorly tolerated in patients with coronary artery disease. Several recent studies have shown that there is an increased incidence of myocardial ischemia when intraoperative heart rates exceed 110/minute. ${ }^{43,44}$

In the present study at 1, 3, 5 and 10 minutes after intubation none of the patients in Group III and Group IV showed heart rate greater than 110 per minute (Table 3). Whereas increase in HR in Group I and Group II above 110 beats/min was noted at various intervals (Table 3). In the study Group III (esmolol $2 \mathrm{mg} / \mathrm{kg}$ body weight) after laryngoscopy and tracheal intubation, the decrease in heart rate was statistically significant as compared to Group I (control) and Group II (esmolol $1 \mathrm{mg} / \mathrm{kg}$ body weight) and this remained statistically significant till 5 minutes after intubation whereas Group IV showed statistically significant decrease in heart rate even at 10 minutes of intubation (Table 4). Findings of present are comparable to those of Oxorn et al. ${ }^{45}$, Sheppard et al. ${ }^{36}$, Korpinen et al. ${ }^{41}$ and Shroff et al. ${ }^{46}$

\section{Effect on Systolic Blood Pressure (SBP)}

There was a slight decrease in systolic blood pressure 30 seconds after giving propofol, which was comparable in all the four groups. A decrease in systolic blood pressure in Groups II, III and IV when compared to their individual baseline values was noted which started at 1 minute after the administration of the study drug and this effect continued till 2 minutes after administering the drug (Table 5). Whereas there was no significant decrease in SBP at both the intervals in Group I.

After intubation the systolic blood pressure were recorded at 1, 3, 5 and 10 minutes in all the groups. There was an increase in SBP at 1 minute after intubation in Group I and Group II (Table 5), whereas in Group III and Group IV, the systolic blood pressure did not increase above baseline values and this effect lasted till 10 minutes after intubation in both Group III and Group IV (Table 5).

\section{Effect on Diastolic Blood Pressure (DBP)}

There was a slight decrease in diastolic blood pressure 30 seconds after giving propofol, which was comparable in all the four groups. There was a decrease in diastolic blood pressure in Groups II, III and IV when compared to their individual baseline values which started at 1 minute after the administration of the study drug and this effect continued till 2 minutes after administering the drug (Table 7). Whereas there was no significant decrease in DBP at both the intervals in Group I. In the present study Group IV, the findings were comparable to the above mentioned study where we noticed a considerable decrease in diastolic blood pressure.

After intubation, readings were again taken at various time intervals of $1,3,5$ and 10 minutes. There was an increase in DBP at 1 minute after intubation in Group I and Group II. In Group III, values were almost comparable to the baseline, whereas no increase was seen in DBP in Group IV (Table 7).

\section{Effect on Mean Arterial Pressure (MAP)}

There was a slight decrease in mean arterial blood pressure 30 seconds after giving propofol, which was comparable in all the four groups. There was a decrease in mean arterial blood pressure in Groups II, III and IV when compared to their individual baseline values which started at 1 minute after the administration of the study drug and this effect continued till 2 minutes after administering the drug (Table 9). Whereas there was no significant decrease in MAP at both the intervals in Group I. At 1 minute after intubation, MAP values increased when compared to their baseline values in Group I and Group II. Whereas in Group III, difference in values of MAP were comparable to its baseline and the effect lasted till 10 minutes after intubation. In Group IV difference in values of MAP at 1 minute after intubation were even lower than the baseline values and the effect lasted till 10 minutes after intubation (Table 9).

Therefore, the attenuation of rise in blood pressure (SBP, DBP and MAP) before and after intubation was significantly seen in groups III and IV i.e. with doses of $2 \mathrm{mg} / \mathrm{kg}$ and $3 \mathrm{mg} / \mathrm{kg}$ only. These were similar to results obtained by various authors in different studies.

Figueredo and Gercia-Fuentes ${ }^{47}$ reported high bolus dose (200 $\mathrm{mg}$ ) of esmolol produced a considerable decrease in diastolic blood pressure. Taneja et al. ${ }^{21}$ from their study concluded that beta blockade with $100 \mathrm{mg}$ esmolol given as a bolus intravenously 3 minutes prior to laryngoscopy and intubation attenuates heart rate and SBP, but no effect was seen on DBP and MAP. Helfman et al. ${ }^{13}$ reported that esmolol $(150 \mathrm{mg}$ ) given as a bolus provided consistent and reliable protection against increases in both heart rate and systolic blood pressure accompanying laryngoscopy and intubation. Similarly Oxoron et al. ${ }^{45}$ and Rathore at al. ${ }^{48}$ reported the efficacy of esmolol in blunting the response to rise in heart rate and blood pressure in a dose dependent manner. However, no consensus has been reached regarding the optimum dose and timing of its delivery. Various workers have used esmolol either as a bolus or as an infusion for attenuation of pressor response.

Previous studies have shown that unique pharmacokinetic behaviour of esmolol makes it well suited for controlling the cardiovascular response to tracheal intubation when using a continuous infusion technique 37,38 reported that esmolol bolus followed by infusion to be useful for preventing the haemodynamic response to suspension laryngoscopy. But the limitation of response was its effectiveness against only increase in heart rate but not blood pressure or QTC interval. Cucchiara et al. ${ }^{38}$ reported an effective blunting of the increases in heart rate and arterial blood pressure with a continuous infusion of esmolol for 12 minutes before intubation $(500 \mathrm{mg} / \mathrm{kg} / \mathrm{min}$ for 4 minutes followed by $300 \mathrm{gg} / \mathrm{kg} / \mathrm{min}$ for 8 minutes) in a group of patients undergoing carotid endarterectomy. Figueredo and Gercia-Fuentes ${ }^{47}$ showed that the effective regimen was a loading dose of $500 \mathrm{mg} / \mathrm{kg} / \mathrm{min}$ over $4 \mathrm{~min}$ followed by continuous infusion dose of 200-300 $\mathrm{mg} / \mathrm{kg} / \mathrm{min}$. However, the dosage regimen and time required for preparation of an infusion may add a degree of complexity to the induction process which is often unnecessary.

As a practical and simple alternative, the results of present study show that esmolol can also be given as an intravenous bolus prior to induction of anaesthesia to control the tachycardia and hypertension secondary to tracheal intubation. The convenience of administration of a bolus dose eliminates the difficulty in arranging the infusion system and precise calculation of drops which may be tedious and take valuable time and resources especially during emergencies. Moreover, the noxious airway 
instrumentation stimuli are often transient and usually do not require the sustained intervention of a continuous esmolol infusion.

The timing of esmolol administration is of prime importance. Since esmolol has a 2 minute distribution half-life and 9 minutes elimination half-life, it is important that 2 minutes or less must elapse after esmolol administration for a peak effect to come.22,49 The timing of administration of the drug also has been variable ranging from 2 minutes to 15 minutes prior to tracheal intubation. Shree et al. ${ }^{35}$ reported that, administration of esmolol 6 minutes prior to intubation had a marginal advantage. In the present study, esmolol given in Group III ( $2 \mathrm{mg} / \mathrm{kg}$ body weight) and Group IV ( 3 $\mathrm{mg} / \mathrm{kg}$ body weight) as a bolus intravenously 3 minutes before tracheal intubation was found to be effective in attenuation of pressor response, and these findings are comparable to those of Shree et al. ${ }^{35}$

Similarly there are no clear guidelines on the dosage of esmolol to effectively prevent haemodynamic stimulation without causing hypotension or bradycardia in the post-intubation period. Most studies report a satisfactory response to esmolol in controlling haemodynamic response when compared with a placebo. ${ }^{35}$ They used esmolol in the dosage of $3 \mathrm{mg} / \mathrm{kg}$. Miller and Martinaeu ${ }^{26}$ had claimed that optimal results can be obtained by using lesser dose of esmolol i.e. $1.5 \mathrm{mg} / \mathrm{kg}$ as compared to $3 \mathrm{mg} / \mathrm{kg}$. They observed adverse effects like hypotension during induction and decrease in cardiac index and ejection fraction following intubation with higher dose of esmolol (3 $\mathrm{mg} / \mathrm{kg}$ ). In the present study, we compared three different doses doses of esmolol i.e. $1 \mathrm{mg} / \mathrm{kg}, 2 \mathrm{mg} / \mathrm{kg}$ and 3 $\mathrm{mg} / \mathrm{kg}$ body weight. No significant adverse effects were noted even with higher doses of esmolol.

\section{CONCLUSION}

In the present study, good control of heart rate and blood pressure was achieved with esmolol $2 \mathrm{mg} / \mathrm{kg}$ body weight which was almost comparable to esmolol $3 \mathrm{mg} / \mathrm{kg}$ body weight. Therefore, if desirable haemodynamic effects can be achieved with lower dose of the drug (esmolol $2 \mathrm{mg} / \mathrm{kg}$ body weight) then there is no rationale for using a higher dose (esmolol $3 \mathrm{mg} / \mathrm{kg}$ body weight). Although in the present study, none of the patients in Group IV (esmolol $3 \mathrm{mg} / \mathrm{kg}$ body weight) had any episode of bradycardia and hypotension that needed active intervention but still one has to be more cautious and vigilant while using higher doses.

Hence, it is concluded that the intravenous esmolol in a dose of 1 $\mathrm{mg} / \mathrm{kg}$ body weight is ineffective in blunting the haemodynamic responses to laryngoscopy and intubation, but esmolol in a dose of $2 \mathrm{mg} / \mathrm{kg}$ body weight given 3 minutes before laryngoscopy and endotracheal intubation is effective in attenuating the haemodynamic responses, without any deleterious effects.

\section{REFERENCES}

1. Coleman AJ, Downing JW, Leary WP, Moyes DG, Styles M. The immediate cardiovascular effects of pancuronium, alcuronium and tubocurarine in man Anaesthesia 1972; 27:415-422.

2. Tomori $Z$ and Widdicombe JG. Muscular, bronchomotor and cardiovascular reflexes elicited by mechanical stimulation of respiratory tract. J Physiol 1969;200:25-49.

3. Burstein CL, Pinto-Lo FJ and Newman W. Electro-cardiographic studies during tracheal intubation; effects during usual routine techniques.Anesthesiology 1950;11:224-237.
4. King BD, Harris LC, Greifenstein FE et al. Reflex circulatory responses to direct laryngoscopy and tracheal intubation performed during general anaesthesia. Anesthesiol 1951;12;556566.

5. Forbes AM and Dally FG. Acute hypertension during induction of anaesthesia and endotracheal intubation in normotensive man. Br J Anaesth 1970;42:618-624.

6. Hassan HG, El-Sharkawy TV, Renck $\mathrm{H}$ et al. Haemodynamic and catecholamine responses to laryngoscopy with Vs without endotracheal intubation. Acta Anaesthesiol Scand 1991;35:442.

7. Hamill JF, Bedford RF, Weaver DC et al. Lidocaine before endotracheal intubation : intravenous or laryngotracheal. Anesthesiology 1981;55:578-581.

8. Stoelting RK. Circulatory changes during dircct laryngoscopy intubation; influence of duration of laryngoscopy with or without lidocaine.Anesthesiology 1977;47: 381-383.

9. Prys-Roberts C, Greene LT, Meloche R et al. Studies of anaesthesia in relation to hypertension II: Haemodynamic consequences of induction endotracheal intubation. $\mathrm{Br} \mathrm{J}$ Anaesth $1971 ; 43: 531-546$.

10. de Clive-Lowe SG, Desmond J and North J. Intravenous lignocaine anaesthesia. Anaesthesia 1958;13:138-146.

11. Hitchcock $P$ and Keown KK. The management of cardiac arrthymias during cardiac surgery.South Med J 1959;52:702.

12. Chraemmer-Jorgensen B, Hoilund-Carlson PF, Marving $J$ et al. Lack of effect of intravenous lidocaine on hemodynamic responses to rapid sequence induction of general anesthesia. Anesth Analg 1986;65:1037-1041.

13. Helfman SM, Gold MI, Dellisser EA et al. Which drug prevents tachycardia and hypertension associated with tracheal intubation: lidocaine, fentanyl or esmolol? Anesth Analg 1991;72:482- 486.

14. Miller RR, Vismar LA and Zelis R. Clinical use of sodium nitroprusside in chronic ischaemic heart disease. Circulation 1975; 51:28-326.

15. Vesey CJ, Cole PV and Simpson PJ. Cyanide and thiocynate concentrations following sodium nitroprusside infusion in man. $\mathrm{Br}$ J Anaesth 1976;2228:651-600.

16. Bower PJ, Peterson JN. Methemoglobinemia after sodium nitroprusside therapy. N Engl J Med 1975;293:865.

17. Colman AJ and Jordan C. Cardiovascular responses to anaesthesia: Influence of beta adrenoreceptor blockade with metoprolol. Anaesthesia 1980;35:972-978.

18. Prys-Roberts C, Foex P, Biro GP et al. Studies of anaesthesia in relation to hypertension vs adrenergic betreceptors

blockade.Br J Anaesth 1973;45:671-681.

19. Bernstein JS, Ebert TJ, Stowe DF et al. Single i/v bolus esmolol prior to rapid sequence induction effectively blunts the intubation response. Anesth Analg 1989;68:S24.

20. Ebert JP, Pearson JD, Gleman S et al. Circulatory responses to laryngoscopy: the comparative effects of placebo, fentanyl and esmolol. Can J Anaesth 1989;36:01-306.

21. Taneja B, Dali JS and Dua CK. Lignocaine $\mathrm{HCl}$ versus esmolol $\mathrm{HCl}$ - Influence on cardiovascular responses to laryngoscopy and tracheal intubation.J Anaesth Clin Pharmacol 2003;19:53-57.

22. Jacque JJ, Gold MI, Grosnoff D et al. Does single bolus esmolol two minutes before intubation prevent tachycardia? Anesth Analg 1989;68:S1- S321.

23. Sum CY, Yacobi A, Kartzinel $R$ et al.Kinetics of esmolol, an ultrashort acting beta blocker, and of its major metabolite. Clin 
Pharmacol Ther 1983;34 :427-434.

24. Sintetos AL, Hulse $J$ and Edward LC. Pritchett pharmacokinetics and pharmacodynamics of esmolol administered as an intravenous bolus. Clin Pharmacol Ther 1987 41:112-117.

25. Parnass S, Rotherberg D and Kerchberger J. A single dose esmolol for prevention of hemodynamic changes of intubation in an ambulatory surgery unit. Anesthesiology 1986;65:528-531.

26. Miller DR and Martinaeu RJ. Esmolol for control of haemodynamic responses during anaesthetic induction. Can J Anaesth 1989;36: S164-S165.

27. Reid LC and Brace BE. Irritation of respiratory tract and its reflex effect on heart. Surg Gynae Obst 1940;70:157-162.

28. Burnstein CL, Pinto-Lo FJ and Newman W. Elecrocardiographic studies during tracheal intubation; effects during usual routine techniques. Anaesthesiology 1950;11:224237.

29. Devault M, Greifenstein FE, Harris LC. Girculatory responsesto endotracheal intubation in light general anaesthesiathe effect of atropine and phentolamine. Anaesthesiology 1960; 21:360-362.

30. Derbyshire DR, Chmielewski A, Fell D et al. Plasma catecholamine responses to tracheal intubation. $\mathrm{Br} J$ Anaesth 1983;55:855-860.

31. Kaplan JA and King SB. The precordial electrocardiographic lead $(\bigvee \neg 5\urcorner)$ in patients who have coronary artery disease. Anesthesiology 1976; $45: 570-574$.

32. Shapiro HM, Wyte SR, Harris AB et al. Acute intraoperative intracranial hypertension in neurosurgical patients: Mechanical and pharmacologic factors. Anesthesiology 1972; 37 : 399-405.

33. Sorenson MB and Jacobsen E. Pulmonary hemodynamics during induction of anesthesia. Anesthesiology 1977;46:246-251.

34. Fox EJ, Sklar GS, Hill CH et al. Complications related to the pressor response to endotracheal intubation. Anesthesiology 1977;47:524-525.

35. Shree RS, Bhadrinarayan V, Ramesh VJ et al. Evaluation of three regimens of esmolol for attenuation of cardiovascular response to endotracheal intubation - A comparison with intravenous lignocaine. J Anaesth Clin Pharmacol 2003;19:45-52.

36. Sheppard S, Eagle CJ and Strunin L. A bolus dose of esmolol attenuates tachycardia and hypertension after tracheal intubation. Can J Anaesth 1990; 37 : 202-205.

37. Menkhaus PG, Reves JG, Kissin I et al. Cardiovascular effects of esmolol in anesthetized humans. Anesth Analg 1985;64:327-334.

38. Cucchiara RF, Benefiel DJ, Matteo RS et al. Evalution of esmolol in controlling increases in heart rate and blood pressure during endotracheal intubation in patients undergoing carotid endarterectomy. Anesthesiology 1986;65:528-531.

39. Withington DE, Ramsay JG, Ralley FE et al. Alteration of heart rate response to intubation by bolus doses of esmolol. Can $\mathrm{J}$ Anaesth 1989; 36: S166-67.
40. Cole CP. Bolus esmolol and postintubation response in patient induced with fentanyl / thiopental. Anesth Analg 1990;70:S65.

41. Korpinen R, Saarnivaara L, Siren $K$ et al. Modification of the haemodynamic responses to induction of anaesthesia and tracheal intubation with alfentanil, esmolol and their combination. Can J Anaesth 1995;42:298-304.

42. Sharma S, Mitra S, Grover VK et al. Esmolol blunts the haemodynamic responses to tracheal intubation in treated hypertensive patients. Can J Anaesth 1996;43:778-782.

43. Stone JG, Foex P, Sear JW et al. Risk of myocardial ischaemia during anaesthesia in treated and untreated hypertensive patients. Br J Anaesth 1988;61:675-679.

44. Slogoff $S$ and Keats AS. Randomized trial of primary anesthetic agent on outcome of coronary artery bypass operations. Anesthesiology 1989;70:179-188.

45. Oxorn D, Knox JWD and Hill J. Bolus doses of esmolol for prevention of perioperative hypertension and tachycardia. Can $\mathrm{J}$ Anaesth 1990;37:206-209.

46. Shroff PP, Mohite SN and Panchal ID. Bolus administration of esmolol in controlling the haemodynamic response to tracheal intubation. J Anaesth Clin Pharmacol 2004;20:69-72.

47. Figueredo $\mathrm{E}$ and Gracia-Fuentes EM. Assessment of the efficacy of esmolol on the haemodynamic changes induced by laryngoscopy and tracheal intubation: a meta-analysis. Acta Anaesthesiology Scand 2001;45:1011-1022.

48. Rathore A, Gupta HK, Tanwar GL et al. Attenuation of pressure response to laryngoscopy and endotracheal intubation with different doses of esmolol. Indian J Anaesth 2002; 46 : 449452.

49. Ahuja S, Singh R and Suneja A. Effect of esmolol on haemodynamic response during endotracheal intubation in patients with pregnancy induced hypertension. J Anaesth Clin Pharmacol 2003;19:269-278.

\section{Source of Support: Nil.}

\section{Conflict of Interest: None Declared.}

Copyright: (c) the author(s) and publisher. IJMRP is an official publication of Ibn Sina Academy of Medieval Medicine \& Sciences, registered in 2001 under Indian Trusts Act, 1882.

This is an open access article distributed under the terms of the Creative Commons Attribution Non-commercial License, which permits unrestricted non-commercial use, distribution, and reproduction in any medium, provided the original work is properly cited.

Cite this article as: Amit Manhas, Shallu Jamwal, Sachin Gupta, Nandita Mehta. Attenuation of the Pressor Response to Laryngoscopy and Endotracheal Intubation with Different Intravenous Doses of Esmolol. Int J Med Res Prof. 2016; 2(5): 8492. 